\title{
Advancement in Vaccination of Broiler Chickens with Genotype- Matched Vaccines to Currently Epidemic Newcastle Disease Virus Genotype VII in Egypt
}

\author{
Sameh Abdel-Moez Amer ${ }^{1 *}$, Mohamed Ahmed $\mathrm{Ali}^{2}$, Ahmed Mohamed Kandeil ${ }^{2}$ and Mohamed Abdel-Aziz Kutkat ${ }^{1}$ \\ ${ }^{1}$ Department of Poultry Diseases, Veterinary Research Division, National Research Centre, P.O. Code 12622, Dokki, Cairo, Egypt. \\ ${ }^{2}$ Centre of Scientific Excellence for Influenza Virus, Environmental Research Division, National Research Centre, P.O. Code 12622, Dokki, Cairo, Egypt. \\ * Corresponding author's Email: drsamehnrc@ hotmail.com; ORCID: 0000-0002-6017-055X.
}

Received: 14 Jul. 2019

Accepted: 15 Aug. 2019

\begin{abstract}
Newcastle disease virus (NDV) outbreaks still occur frequently in Egypt in spite of the heavy implementation of classic NDV vaccines for a long time ago, where NDV genotype VII has become the dominant genotype in Egypt from 2012 until now. Many previous studies have recommended using genotype-matched NDV vaccines against the epidemic virus for providing better protection and minimizing virus shedding. Therefore, the present study evaluated the efficacy of two available live NDV vaccines in Cobb 500 broilers. The group A and B (20 birds each) were vaccinated with live attenuated NDV vaccines genotype VII and II, respectively with double doses at 5 and 19 days of age. Also, group C consisting of 20 unvaccinated birds was studied as a control group. The efficacy of live vaccines was determined using virus challenge test. Hence, all groups were challenged with velogenic NDV genotype VIId at a dose equivalent to $10^{6.0} 50$ percent Embryo Infective Dose $\left(\mathrm{EID}_{50}\right)$ via the intramuscular route at 28 daysold. Serum antibodies level was assessed by hemagglutination inhibition test. Moreover, virus shedding was measured by $\mathrm{EID}_{50}$. The obtained results indicated that vaccinated birds had similar haemagglutination titers with no significant difference prior challenge. Meanwhile, group A showed significant protection against mortality, as well as a significant reduction in virus shedding 7 days post-challenge compared to Group B. We concluded that live recombinant-genotype VII vaccine homologous to challenge virus could improve the protective efficiency in chicken against NDV compared to live classic genotype II vaccine. It is suggested that the implementation of genotypematched NDV vaccines confer better protection in commercial broilers vaccination programs.
\end{abstract}

Key words: Broilers, Genotype-matched vaccine, Genotype VII, Newcastle disease virus

\section{INTRODUCTION}

Newcastle Disease (ND) is a highly contagious viral infection of avian species, including domestic poultry. The causative agent of ND is known as avian paramyxovirus 1 or ND Virus (NDV) which is an enveloped, singlestranded, non-segmented and negative-sense RNA virus. The NDV is a member of Avulavirus genus within the Paramyxovirinae subfamily of Paramyxoviridae family in the Mononegavirales order (Mayo, 2002). Within the single serotype, NDV strains are divided into two classes. Viruses from class I comprise only one genotype and mainly isolated from waterfowl, shorebirds, and wild birds. Class II viruses are found in both wild and domestic avian species and are subdivided into 18 genotypes based on fusion protein gene sequence and phylogenetic analysis (Kim et al., 2007; Miller et al., 2010).
A major shift in the types of NDV strains caused by genotype VII of class II virus which has been identified as prevalent in poultry since it was first detected in the 2000 s in China (Liu et al., 2003; Zhang et al., 2010) with severe outbreaks in Europe, Africa, the Middle East, South America and Asia (Lomniczi et al., 1998; Abolnik et al., 2004). Genotype VII of NDV was first identified in Egypt by Radwan et al. (2013), and later, presence of other Egyptian NDV genotype VII isolates, as well as concurrent outbreaks, were reported successfully by several studies (Hussein et al., 2014; Abdel -Aziz et al., 2016; Ewies et al., 2017).

Live-attenuated NDV vaccines are generally used in the first weeks of life in broilers, layers, and breeders, by either systemic or the respiratory route, in order to reduce the risk of infection with virulent strains. Furthermore, live vaccines administered by eye drop or orally have been 
found to induce protective mucosal immunity mediated by Immunoglobulin (Ig) A and provide potent systemic immunity alongside their excellent safety profile (Miller and Koch, 2013). Thus, a highly immunogenic and safe live vaccine can provide a chance to enhance herd immunity through a massive vaccination program by the respiratory route (Al-Garib et al., 2003).

Application of an intensive vaccination programs with annual use of ND vaccines has increased, but ND outbreaks have still occurred periodically across the world with elevated economic losses, mainly resulting from higher mortalities and decreased egg production rates; even in well-vaccinated farms have raised questions about the protective efficacy of conventional vaccines and the antigenic variation of NDV (Cho et al., 2008). Nowadays, LaSota and B1 NDV strains used to produce ND vaccines, have phylogenetically the same genotype of viruses isolated in the 1940s, but are genotypically different or dis-matched from strains causing the recent outbreaks of $\mathrm{ND}$, so as to, recent studies were carried out on the role of genotype-matched vaccines in the control of NDV epidemics which found to provide better protection and reduce virus shedding from infected birds against challenge with virulent genotype VII NDV (Hu et al., 2011; Yang et al., 2016). Therefore, the goal of this study was to explore the effects of the matching genotype of live NDV vaccine strain to the likely virulent challenge virus in commercial broiler chickens on the level of protection and virus shedding.

\section{MATERIALS AND METHODS}

\section{Ethical approval}

The animal experiments were carried out in strict accordance with and adherence to the relevant policies regarding animal handling as mandated under international, national, and /or institutional guidelines for the care of animals and were approved by the Research Ethical Committee at the National Research Centre, Cairo, Egypt.

\section{Viruses and vaccines}

The virus used for the challenge purpose was characterized by sequencing as velogenic NDV (vNDV) genotype VIId designated as "NDV/Chicken/EGMN/NRC/2015" with a Genbank accession number of (MF418020.1). The virus was propagated in nine-day-old specific pathogen-free embryonated chicken eggs via allantoic cavity inoculation. The virus challenge dose, equal to $6 \log _{10}$ embryo infective dose $\left(\mathrm{EID}_{50}\right)$ per $0.5 \mathrm{ml}$, was administered intramuscularly to chickens (OIE, 2012).

Live attenuated NDV vaccines: freeze-dried vaccines containing live attenuated NDV genotype VII (KBNPC4152R2L strain, Himmvac ${ }^{\circledR}$ Dalguban N Plus 2000 doses) and genotype II (LaSota strain, Jovac ND LaSota ${ }^{\circledR}$ 1000 doses) were supplied by local agencies. The vaccine doses, equal to $6 \log _{10} \mathrm{EID}_{50}$ in $20 \mu 1$ per bird, were administered according to the manufacturer's recommendations.

\section{Serology}

Blood serum was collected pre and post-challenge (at 14, 21, 28 and 35 days of age) from all birds and evaluated by Hemagglutination Inhibition (HI) assay. The HI assay was performed using inactivated NDV antigen (LaSota strain) according to standard procedures with four haemagglutinating units of virus/ antigen in $0.050 \mathrm{ml}$ (OIE, 2012).

\section{Virus shedding}

Shedding of the virus was determined by collecting oropharyngeal and cloacal swabs at 3 and 7 days postchallenge (dpc), respectively. Swabs were collected in 1.5 $\mathrm{mL}$ of phosphate buffer saline supplemented with a final concentration of gentamicin $(200 \mu \mathrm{g} / \mathrm{mL})$, penicillin $\mathrm{G}$ (2000 units $/ \mathrm{mL}$ ) and amphotericin B $(4 \mu \mathrm{g} / \mathrm{mL})$. The presence of the virus was determined by inoculating clarified swab samples into nine-days-old embryonated specific-pathogen-free chicken eggs and conducting HA assay three days later. Pools of swabs $(n=3$ per group) from the same group were clarified via centrifugation at $1000 \times \mathrm{g}$ for 15 minutes. Virus titers were calculated by using the standard methods described by (OIE, 2012) and were reported as mean $\mathrm{EID}_{50} / 0.1 \mathrm{ml}$ on a $\log _{10}$ scale.

\section{Chicken experiments}

Sixty one-day-old commercial broiler chicks (Cobb $500^{\circledR}$ ) were provided by the certified local hatchery, divided into three experimental groups (A, B and C) of 20 birds each and reared in separate units with strict biosecurity level. Conventional animal welfare regulations and feed standards were taken into account. Chickens in group A vaccinated with live attenuated NDV vaccine (genotype VIId strain) on 5 and 19 days of age via the oculonasal route. Meanwhile, group $\mathrm{B}$ received live attenuated NDV vaccine genotype II (LaSota strain) on day 5 and 19 of age through the oculonasal route. In addition, birds in group $\mathrm{C}$, as a control group, did not 
receive vaccines. The three groups were challenged with vNDV genotype VIId on 28 days of age (Table 1).

Table 1. NDV vaccination and challenge schedule in Cobb 500 broiler chickens

\begin{tabular}{lcccc}
\hline Group & $\begin{array}{c}\text { Number } \\
\text { of birds }\end{array}$ & Type & $\begin{array}{c}\text { Vaccination regimen } \\
\text { time (day of }\end{array}$ & $\begin{array}{c}\text { Challenge } \\
\text { time } \\
\text { (day of age) }\end{array}$ \\
\hline A & 20 & Live. GVII & 5 \& 19 & 28 \\
\hline B & 20 & Live.GII $^{\mathbf{2}}$ & 5 \& 19 & 28 \\
\hline $\mathrm{C}$ & 20 & None & None & 28 \\
\hline
\end{tabular}

${ }^{1}$ Live attenuated NDV genotype VII vaccine via oculonasal route; ${ }^{2}$ Live attenuated NDV genotype II vaccine via oculonasal route; ${ }^{3}$ Challenge with velogenic NDV (genotype VIId) via intramuscular route.

\section{Statistical analysis}

Data were analyzed by one-way ANOVA with Tukey's post hoc test performed using SPSS version 21 software (SPSS Inc., USA) to determine the significance of differences between treatment and control groups. A pvalue $\leq 0.05$ was considered statically significant.

\section{RESULTS}

\section{Protective efficacy of live NDV vaccines in broilers}

Non-vaccinated infected broilers displayed marked depression with severe respiratory signs and greenish diarrhea from 3 to $4 \mathrm{dpc}$ and with a mortality rate of $100 \%$ at 4 and $5 \mathrm{dpc}$. In contrast, the vaccinated birds in group $A$ and $\mathrm{B}$ revealed weaker or much less clinical signs (including reduced activity, depression with mild to moderate respiratory manifestations) compared to unvaccinated controls. As well as, vaccinated chickens exhibited varying degrees of protection with significantly lower mortality rates started at $4 \mathrm{dpc}$ in comparison with the non-vaccinated group. In general, group A conferred significant protection against mortality with $25 \%$ mortality rate (five out of 20 chickens) at 5 and $6 \mathrm{dpc}$, whilst mortality rate in group B was $60 \%$ (12 out of 20 birds) at 5, 6 and $7 \mathrm{dpc}$, as shown in table 2.

Table 2. The mortality rate in Cobb 500 broiler chickens 7 days post-challenge with vNDV (Genotype VII)

\begin{tabular}{lcccc}
\hline Group & $\begin{array}{c}\text { Number } \\
\text { of birds }\end{array}$ & $\begin{array}{c}\text { Challenge } \\
\text { time } \\
\text { (day of age) }\end{array}$ & $\begin{array}{c}\text { The mortality rate at 7 days } \\
\text { Post-challenge }\end{array}$ \\
\cline { 3 - 5 } & 20 & 28 & 5 & Number \\
\hline $\mathrm{A}^{\mathbf{a}, \mathbf{b}}$ & 20 & 28 & 12 & 25 \\
$\mathrm{~B}^{\mathbf{b}}$ & 20 & 28 & 20 & 60 \\
$\mathrm{C}$ & &
\end{tabular}

In necropsy examination, hemorrhagic spots and/or petechial hemorrhages were found in proventricular glands and also ulceration of cecal tonsils with splenomegaly and severe tracheitis were observed in non-vaccinated infected controls. While, similar, mild or even no gross lesions were observed in vaccinated challenged groups.

\section{Serology}

Vaccinated groups A and B exhibited positive HI titers for NDV, which increased throughout the vaccination course with significant higher titers from control group $\mathrm{C}$ at all designated tested days. For groups $\mathrm{A}$ and $\mathrm{B}$, the antibody titers produced respectively by live NDV genotype VII vaccine or live NDV genotype II vaccine were comparable to each other and not significantly different ranging from 2.22 to $5.73 \mathrm{Vs} 2.81$ to 6.11 , respectively pre- and post-challenge. Moreover, HI titers were low in non-vaccinated infected controls ranging from 1.73 to 1.91 up to challenge day. The data was shown in Table 3.

Table 3. Serology pre and post-challenge with vNDV strain (Genotype VII)

\begin{tabular}{ccccccc}
\hline \multirow{2}{*}{ Group } & \multirow{2}{*}{$\begin{array}{c}\text { Number } \\
\text { of birds }\end{array}$} & $\begin{array}{c}\text { Challenge } \\
\text { time (day } \\
\end{array}$ & & \multicolumn{4}{c}{$\begin{array}{c}\text { HI titer means Log-2 } \\
\text { of age) }\end{array}$} & $\mathbf{1 4}$ & $\mathbf{2 1}$ & $\mathbf{2 8}$ & $\mathbf{3 5}$ \\
\cline { 4 - 7 } & & 28 & 2.22 & 3.11 & 4.23 & 5.73 \\
$\mathrm{~A} *$ & 20 & 28 & 2.81 & 3.88 & 4.82 & 6.11 \\
$\mathrm{~B} *$ & 20 & 28 & 1.73 & $1.61^{\star}$ & 1.91 & $\mathrm{NT}$ \\
$\mathrm{C}$ & 20 & 28 &
\end{tabular}

*Significant difference compared to control group $\mathrm{C}(\mathrm{P}<0.05)$. ${ }^{\star} \mathrm{HI}$ titre $\leq$ 2 Log- ${ }_{2}$ considered negative (OIE, 2012). N : Number of tested samples. NT: Not tested (All Birds of this group died at 4 and 5 days postchallenge).

\section{Virus shedding}

All of the oropharyngeal swabs from control and vaccinated birds were positive with clearly detectable titers, although it was significantly reduced in both groups $\mathrm{A}$ and $\mathrm{B}$ compared to control group $\mathrm{C}$ at $3 \mathrm{dpc}$. Meanwhile, no significant difference was detected in oral shedding at $3 \mathrm{dpc}$ between group A and B (5.2 VS 5.7 Log 10 EID $\left._{50} / 0.1 \mathrm{ml}\right)$. While, cloacal shedding was significantly lower in group $\mathrm{A}$ in comparison to group $\mathrm{B}$ (3.7 VS 5.4 $\log _{10} \mathrm{EID}_{50} / 0.1 \mathrm{ml}$ ), at $7 \mathrm{dpc}$, as shown in table 4 .

Table 4. Viral shedding oropharyngeal and cloacal swabs collected from Cobb 500 broiler chickens at 3 and 7 days post-challenge, respectively with vNDV (Genotype VII)

\begin{tabular}{lcccc}
\hline Group & \multirow{2}{*}{$\begin{array}{c}\text { Number } \\
\text { of birds }\end{array}$} & $\begin{array}{c}\text { Challenge } \\
\text { time } \\
\text { (day of age) }\end{array}$ & \multicolumn{2}{c}{ Virus Shedding * } \\
\cline { 5 - 5 } & 20 & 28 & $\begin{array}{c}\text { 3 dpc } \\
\text { (oropharyngeal) }\end{array}$ & $\begin{array}{c}\text { 7 dpc } \\
\text { (Cloacal) }\end{array}$ \\
\hline $\mathrm{A}^{\mathbf{a}, \mathbf{b}}$ & 20 & 28 & $5.2^{\mathbf{a}}$ & $3.7^{\mathbf{b}}$ \\
$\mathrm{B}^{\mathbf{b}}$ & 20 & $5.7^{\mathbf{a}}$ & 5.4 \\
$\mathrm{C}$ & 20 & 28 & 7.5 & $\mathrm{NT}$
\end{tabular}

*Viral titers (log-10) expressed as mean embryo infectious doses per 0.1 $\mathrm{ml}$ from a pool of oral or cloacal swabs ( $\mathrm{n}=3$ per group). ${ }^{\text {a Significant }}$ difference from control group $\mathrm{C}$ at $3 \mathrm{dpc}(\mathrm{P}<0.05)$. ${ }^{\mathrm{b}}$ Significant difference from group $\mathrm{B}$ at $7 \mathrm{dpc}(\mathrm{P}<0.05)$. NT: None tested (All Birds of this group died at 4 and 5 days post -challenge). dpc: days post-challenge. 


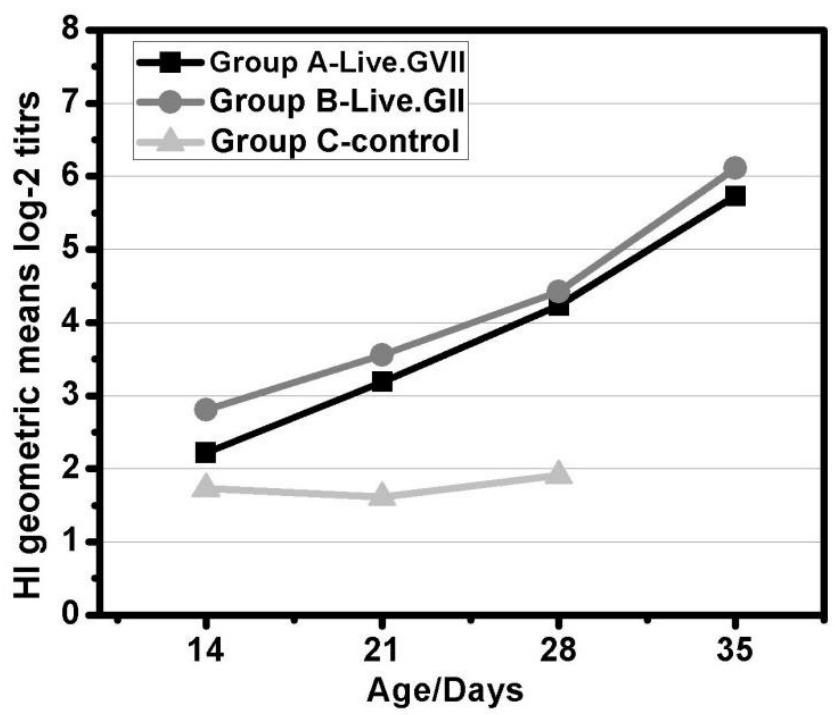

Figure 1. Antibody dynamics of vaccinated and unvaccinated Cobb 500 broiler chickens. Geometric mean Haemagglutination titers (log-2) for sera collected on 14, 21, 28 and 35 days of age (pre-and post-challenge).

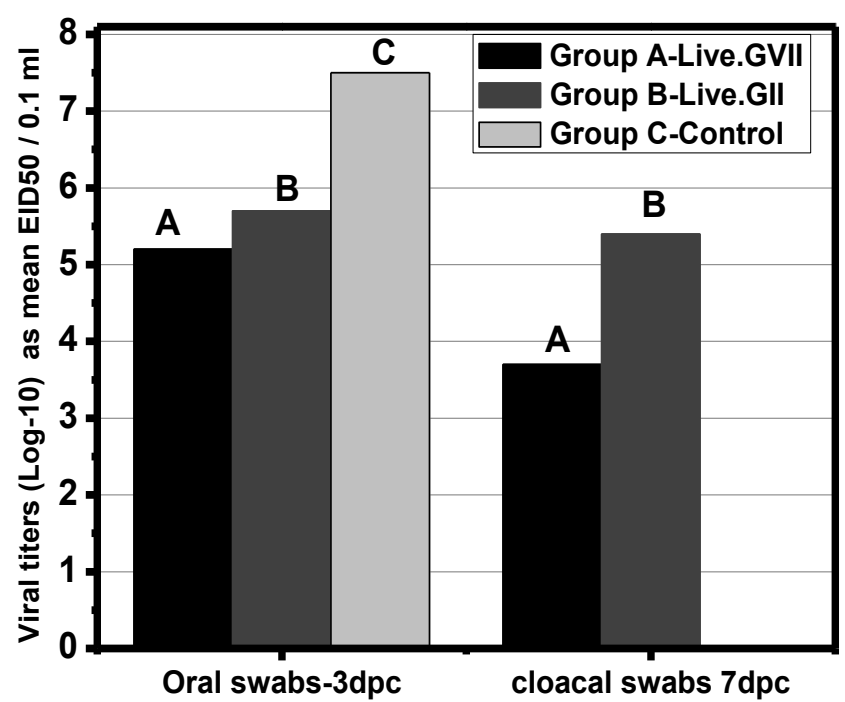

Figure 2. Viral shedding of oral swabs at $3 \mathrm{dpc}$ and cloacal swabs at $7 \mathrm{dpc}$ in Cobb 500 broiler chickens unvaccinated or vaccinated with live attenuated genotypes (VII or II) NDV vaccines and challenged with vNDV (genotype VIId) expressed as (log-10) mean EID $50 / 0.1 \mathrm{ml}$.

\section{DISCUSSION}

Despite extensive vaccination regimen, waves of ND outbreaks continue to cause mortality and severe economic losses in poultry flocks (Shahar et al., 2018). The virus that was used in the present challenge was isolated from Egyptian poultry flocks that were heavily vaccinated thus raising the importance of eliminating NDV infection of the flocks.

In spite of all NDV isolates are considered to be of one serotype, vaccination with any NDV strain couldn't provide equal protection against all isolates. Therefore, in fully controlled vaccination experiments it was found that vaccination with the live attenuated vaccine strains was not sufficient to provide protection for birds against challenge with virulent field isolates (Kapczynski and King, 2005). However, vaccines composed of strains more homologous to the challenge virus are more efficient at decreasing morbidities, mortalities, and virus shedding (Miller et al., 2007; Cho et al., 2008; Kim et al., 2017). In the present study, levels of protection induced by the live recombinant genotype VII and live genotype II LaSota NDV vaccines were compared following challenge with the recently acquired genotype VII NDV isolate in commercial broiler chickens.

In birds vaccinated with live vaccines against NDV, subsequently, Immunity develops very early and neutralizing antibodies can be detected 6-10 days after vaccination (Al-Garib et al., 2003; Kapczynski et al., 2013). Furthermore, it is expected that the protection rate reaches a peak near 3 weeks after the initial vaccination and then steadily starts to decrease (Vrdoljak et al., 2017). In the current study, vaccinated groups received the first dose of NDV live vaccine on five days-old to avoid virus neutralization by maternally derived antibodies which are decreased by half every 3-4 days (Umino et al., 1987), and the second dose was administered two weeks later, with the aim to test whether the protection rate will be maintained until the end of the production period. Consequently, the challenge virus was inoculated at 28 days of age, which is the case of birds vaccinated two times two weeks interval and challenged after 23 days from the first dose. Although chickens will not be infected in the field through injection, so far, the intramuscular injection is the recommended route according to (Alexander and Senne, 2008; OIE, 2012) and also for this reasons the eye-drop route did not allow for exacting delivery of infective virus to each bird.

Clinical signs in the challenged birds included usual symptoms related to infection with vNDV such as ruffled feathers, depression, tremor, diarrhea and paralysis which in most cases led to fatality, although a number of vaccinated birds showed much less signs of mild nasal discharge and depression and were found to recover fully by the end of the observation period, especially in group A (genotype VII) that was apparently more protected against clinical disease compared to group B (live LaSota vaccine) as 
previously mentioned by (Vrdoljak et al., 2018; Shahar et al., 2018).

In addition to clinical signs, gross post-mortem changes were apparently detected, since in poultry commonly seen as hemorrhages in the spleen, tracheal, proventriculus and cecal tonsils. As well as, the spleen may be enlarged, mottled and necrotic (Susta et al., 2011; Miller and Koch, 2013) which were observed almost in susceptible non-vaccinated flocks which were in agreement with the obtained findings in the present study.

Almost all genotype VII NDV isolates are velogenic strains and resulting in higher mortality rates in poultry reached $100 \%$ (Zhang et al., 2010). Accordingly, trials of vaccination against genotype VII NDV challenge have been carried out by (Dortmans et al., 2014; Susta et al., 2014) concluded that adequate application of live attenuated or inactivated NDV vaccines provided sufficient protection in chickens challenged with vNDV. Consequently, in the current study, the live genotype VII NDV vaccine was introduced into the current commercial broiler vaccination program and its efficacy against vNDV challenge was assessed. Evaluation of the vaccination program showed that Cobb 500 broilers treated with live genotype II vaccines (LaSota) on the day 5 and 19 days of age were more susceptible to vNDV challenge than live NDV vaccine genotype VII at the same designated days-old. These results confirmed that introduction of the recombinant genotype VII NDV live vaccine provided significant protection against mortality compared to live genotype II vaccines (LaSota) at $7 \mathrm{dpc}$, and are consistent with previous investigations by (Cho et al., 2008; Roohani et al., 2015).

Titers of anti-NDV antibodies were measured at second week (post-initial vaccinal dose), one-week prior challenge and also one-week post-challenge. Both live attenuated genotype VII and II NDV vaccines induced a significant immune response compared to non-vaccinated controls. While no significant difference was detected between the vaccinated groups of A and B. However, group B showed slightly higher HI titers than genotype VII in group A which may be due to LaSota vaccine used as mentioned by Miller et al. (2007). The aforementioned study detected higher HI titers when the antigen used in the assay was homologous to the vaccine antigen. Generally, it should be emphasized that the level of antibody titers produced by NDV is not ever the optimum estimate of protection against virus challenge. Correlation between serum anti-NDV titer and protection against NDV challenge is usually more reliable in birds vaccinated with inactivated vaccines because the major immunity induced by killed viruses is a humoral response (Goddard et al., 1988; Reynolds and Maraqa, 2000). In birds vaccinated with live attenuated vaccines, cellular and local immunity contribute considerably to the protection rate by decreasing disease and transmission potential (Kapczynski et al., 2013). In the study by Vrdoljak et al. (2017) have been found that in spite of little or no serum antibody response detected in broilers vaccinated with live attenuated NDV vaccine, birds still showed an almost high level of protection against virus challenge, probably as a result of non-humeral and innate immunity. Thus, the often-used detection of antibody titers in the evaluation of flock's protection against NDV after vaccination with live attenuated vaccines may under-estimate the actual protection rate (Vrdoljak et al., 2018).

$\mathrm{HI}$ antibody titer is one of the most direct factors to estimate the protection induced by ND vaccines, as it corresponds with protection level. More commonly, HI titers of $6 \mathrm{Log}-2$ or higher are what typically thought of being protective (Raghul et al., 2006). The obtained results in the current investigation emphasized this finding and further revealed that even mortalities and virus shedding following challenge with vNDV were not completely inhibited when HI titers of both live NDV vaccines genotype VII and II were 4.23 and 4.82, respectively at challenge day. Although, live genotype VII vaccine provided significant protection against mortality and viral shedding in compared to live genotype II vaccine at $7 \mathrm{dpc}$. This finding confirmed that the genotype VII vaccine could reasonably be expected to be effective against vNDV genotype VII infection than genotype II vaccine especially when HI titers are below the protective levels.

Currently, the most widely used vaccines that belong to genotype II such as LaSota provides protection against morbidity and mortality caused by a virulent NDV. Nonetheless, not fully prevents infection or virus shedding in vaccinated birds (Cho et al., 2008). Several previous studies have demonstrated that genotype-matched vaccinations reduce virus shedding following challenge with vNDV isolates more efficiently in comparison to the LaSota strain (Cho et al., 2008; Hu et al., 2009; Miller et al., 2009; Roohani et al., 2015). Similar findings were obtained in the current study in which the live genotype VII vaccine was found to provide better control and prevention of virus shedding after NDV infection. The vaccination of broiler chickens with recombinant genotype VII live vaccine reduced oropharyngeal shedding of virus compared to the LaSota vaccine at $3 \mathrm{dpc}$ with a subsequent significant reduction of cloacal shedding compared to LaSota live vaccine at $7 \mathrm{dpc}$. 


\section{CONCLUSION}

In conclusion, the results of vaccination efficacy indicated that the genotype-matched vaccine (live genotype VII) to the challenge virus was able to reduce virus shedding significantly as well as provided significant protection against mortality compared to classic antigenicallydivergent vaccines (live genotype II, LaSota) in commercial Cobb 500 broiler chickens. However, both vaccines did not confer adequate protection. Therefore, further studies are needed to evaluate more intensive live vaccination regimens or even introduce inactivated NDV vaccines in broiler vaccination programs in order to achieve better protection against currently epidemic vNDV infection.

\section{DECLARATIONS}

\section{Acknowledgments}

The authors thank the laboratory of Veterinary Vaccines Technology (VVT), Centre of the Scientific Excellence, National Research Centre, Cairo, Egypt for all kind of supports.

\section{Competing interests}

All authors have no conflict of interest.

\section{Consent to publish}

The authors grant the publisher the sole and exclusive license of the full copyright in the contribution. Consequently, the publisher shall have the exclusive right throughout the world to publish and sell the contribution in all languages and all other forms of electronic publication.

\section{Author's contribution}

All authors equally participated in design, experimental procedure, writing, revised, and reviewing the manuscript.

\section{REFERENCES}

Abd El-Aziz MN, Abd El-Hamid HS, Ellkany HF, Nasef SA, Nasr SM and El Bestawy AR (2016). Biological and Molecular Characterization of Newcastle Disease Virus Circulating in Chicken Flocks, Egypt, During 2014-2015. Zagazig $\begin{array}{llll}\text { Veterinary } \quad \text { Journal, } 44 & 44 \text { (1): }\end{array}$ DOI: https://10.21608/ZVJZ.2016.7827

Abolnik C, Horner RF, Bisschop SP, Parker ME, Romito M and Viljoen GJ (2004). A phylogenetic study of South African Newcastle disease virus strains isolated between 1990 and 2002 suggests epidemiological origins in the Far East. Archive of Virology, 149 (3): 603-619. DOI: https://10.1007/s00705-003-0218-2.
Alexander DJ and Senne DA (2008). Newcastle Disease and Other Avian Paramyxoviruses. In: L. Dufour-Zavala, D.E. Swayne, J.R.Glisson, M.W. Jackwood, J.E. Pearson, W.M Reed, P.R Woolcock. (Editors), A Laboratory Manual for the Isolation, Identification and Characterization of Avian Pathogens, 4th Edition, American Association of Avian Pathologists, Athens, GA, pp. 135-141.

Al-Garib SO, Gielkens ALJ, Gru YSE and Koch G (2003). Review of Newcastle disease virus with particular references to immunity and vaccination. Worlds Poultry Science Journal, 59: 185-200. DOI: https://10.1079/wps20030011.

Cho SH, Kwon HJ, Kim TE, Kim JH, Yoo HS, Park MH, Park YH and Kim SJ (2008). Characterization of a recombinant Newcastle disease vaccine strain. Clinical and Vaccine Immunology, $15 \quad$ (10): $1572-1579 . \quad$ DOI: https://10.1128/CVI.00156-08.

Dortmans JC, Venema-Kemper S, Peeters BP and Koch GF (2014). Field vaccinated chickens with low antibody titers show equally insufficient protection against matching and non-matching genotypes of virulent Newcastle disease virus. Veterinary Microbiology, 172 (1-2): 100-107. DOI: https://10.1016/j.vetmic.2014.05.004.

Ewies SS, Ali A, Tamam SM and Madbouly HM (2017). Molecular characterization of Newcastle disease virus (genotype VII) from broiler chickens in Egypt. Beni-Suef University Journal of Basic and Applied Sciences, 6 (3): 232-237. DOI: https://10.1016/j.bjbas.2017.04.004.

Goddard RD, Nicholas RA and Luff PR (1988). Serology-based potency test for inactivated Newcastle disease vaccines. Vaccine, 6: 530-532.

Hu S, Ma H, Wu Y, Liu W, Wang X, Liu Y and Liu X (2009). A vaccine candidate of attenuated genotype VII Newcastle disease virus generated by reverse genetics. Vaccine, 27: 904-910. DOI: https://10.1016/j.vaccine.2008.11.091.

$\mathrm{Hu} \mathrm{Z}$, Hu S, Meng C, Wang X, Zhu J and Liu X (2011). Generation of a genotype VII Newcastle disease virus vaccine candidate with high yield in embryonated chicken eggs. Avian Diseases, 55 (3): 91-397. DOI: https://10.1637/9633-122410-Reg.1.

Hussein HA, Emara MM and Rohaim MA (2014). Molecular characterization of Newcastle disease virus Genotype VII in Avian influenza $\mathrm{H} 5 \mathrm{~N} 1$ infected broiler flock in Egypt. International Journal of Virology, 10 (1): 46-54. DOI: https://10.3923/ijv.2014.46.54.

Kapczynski DR and King DJ (2005). Protection of chickens against overt clinical disease and determination of viral shedding following vaccination with commercially available Newcastle disease virus vaccines upon challenge with highly virulent virus from the California 2002 exotic Newcastle disease outbreak. Vaccine, 23: 3424-3433. DOI: https://10.1016/j.vaccine.2005.01.140.

Kapczynski DR, Afonso CL and Miller PJ (2013). Immune responses of poultry to Newcastle disease virus. Developmental and Comparative Immunology, 41(3): 44753. DOI: https://10.1016/j.dci.2013.04.012.

Kim LM, King DJ, Curry PE, Suarez DL, Swayne DE, Stallknecht DE, Slemons RD, Pedersen JC, Senne DA, Winker K and Afonso CL (2007). Phylogenetic diversity among low- 
virulence Newcastle disease viruses from waterfowl and shorebirds and comparison of genotype distributions to those of poultry-origin isolates. Journal of Virology, 81: 12641-12653. DOI: https://10.1128/JVI.00843-07.

Kim SH, Chen Z, Yoshida A, Paldurai A, Xiao S and Samal SK (2017). Evaluation of fusion protein cleavage site sequences of Newcastle disease virus in genotype matched vaccines. PLOS ONE, 12: 1-11. DOI: https://10.1371/journal.pone.0173965.

Liu XF, Wan HQ, Ni XX, Wu YT and Liu WB (2003). Pathotypical and genotypical characterization of strains of Newcastle disease virus isolated from outbreaks in chicken and goose flocks in some regions of China during 19852001. Archives of Virology, 148: 1387-1403. DOI: https://10.1007/s00705-003-0014-z.

Lomniczi B, Wehmann E, Herczeg J, Ballagi-Pordny A, Kaleta EF, Werner O, Meulemans G, Jorgensen PH, Man AP, Gielkens AL, et al. (1998). Newcastle disease outbreaks in recent years in Western Europe were caused by an old (VI) and a novel genotype (VII). Archives of Virology, 143: 4964.

Mayo MA (2002). A summary of taxonomic changes recently approved by ICTV. Archives of Virology, 147: 1655-63. DOI: https://10.1007/s007050200039.

Miller PJ and Koch G (2013). Newcastle Disease, Other Avian Paramyxoviruses, and Avian Metapneumovirus Infections. In: D. E. Swayne (Editor), Diseases of Poultry, 13th Edition. John Wiley \& Sons, Inc., p. 1408. DOI: https://10.1002/9781119421481.ch3.

Miller PJ, Decanini EL and Afonso CL (2010). Newcastle disease: Evolution of genotypes and the related diagnostic challenges. Infection, Genetics and Evolution, 10: 26-35. DOI: https://10.1016/j.meegid.2009.09.012.

Miller PJ, King DJ, Afonso CL and Suarez DL (2007). Antigenic differences among Newcastle disease virus strains of different genotypes used in vaccine formulation affect viral shedding after a virulent challenge. Vaccine, 25: 7238-7246. DOI: https://10.1016/j.vaccine.2007.07.017.

OIE (2012). Newcastle disease. Chapter 2.3.14, OIE Manual of Standards for Diagnostic Tests and Vaccines, NB: Version adopted by the World Assembly of Delegates of the OIE.

Radwan MM, Darwish SF, El-Sabagh IM, El-Sanousi AA and Shalaby MA (2013). Isolation and molecular characterization of Newcastle disease virus genotypes II and VIId in Egypt between 2011 and 2012. Virus Genes, 47: 311-316. DOI: https://10.1007/s11262-013-0950-y.

Raghul J, Raj GD, Manohar BM and Balachandran C (2006). Protection of the reproductive tract of young chicks by Newcastle disease virus induced haemagglutination inhibition antibodies. Veterinary Research Communications, 30 (1): 95-102. DOI: https://10.1007/s11259-005-3141-z.

Reynolds DL and Maraqa AD (2000). Protective immunity against Newcastle disease: the role of antibodies specific to Newcastle disease virus polypeptides. Avian Diseases, 44: 138-144.

Roohani K, Tan SW, Yeap SK, Ideris A, Bejo MH and Omar AR (2015). Characterization of genotype VII Newcastle disease virus (NDV) isolated from NDV vaccinated chickens, and the efficacy of LaSota and recombinant genotype VII vaccines against challenge with velogenic NDV. Journal of Veterinary Science, 16 (4): 447-457. DOI: https://10.4142/jvs.2015.16.4.447.

Shahar E, Haddas R, Goldenberg D, Lublin A, Bloch I, Hinenzon $\mathrm{N}$ and Pitcovski J (2018). Newcastle disease virus: is an updated attenuated vaccine needed? Avian Pathology, 47: 467-478. DOI: https://10.1080/03079457.2018.1488240.

Susta L, Jones ME, Cattoli G, Cardenas-Garcia S, Miller PJ, Brown CC and Afonso CL (2014). Pathologic Characterization of Genotypes XIV and XVII Newcastle Disease Viruses and Efficacy of Classical Vaccination on Specific Pathogen-Free Birds. Veterinary Pathology, 52 (1): 120-131. DOI: https://10.1177/0300985814521247.

Susta L, Miller PJ, Afonso CL and Brown CC (2011). Clinicopathological characterization in poultry of three strains of Newcastle disease virus isolated from recent outbreaks. Veterinary Pathology, 48: 349-360. DOI: https://10.1177/0300985810375806.

Umino Y, Kohama T, Kohase M, Sugiura A, Klenk HD and Rott $R$ (1987). Protective effect of antibodies to two viral envelope glycoproteins on lethal infection with Newcastle disease virus. Archives of Virology, 94 (1): 97-107.

Vrdoljak A, Halas M and Süli T (2017). Vaccination of broilers against Newcastle disease in the presence of maternally derived antibodies. Tierärztliche Praxis Großtiere, 45: 151158. DOI: https://10.15653/TPG-160661.

Vrdoljak A, Halas M and Süli T (2018). Efficacy of Live Attenuated Vaccines against Newcastle Disease in Commercial Broilers. Journal of Veterinary Medicine and Research, 5(2): 1123.

Yang H, Zhao J, Xue J, Yang Y and Zhang G (2016). Antigenic variation of LaSota and genotype VII Newcastle disease virus (NDV) and their efficacy against challenge with velogenic NDV. Vaccine, 35: 27-32. DOI: https://10.1016/j.vaccine.2016.11.048.

Zhang R, Pu J, Su JL, Zhao JX, Wang XZ and Zhang SP (2010). Phylogenetic characterization of Newcastle disease virus isolated in the mainland of China during 2001-2009. Veterinary Microbiology, 141(3-4): 246-257. DOI: https://10.1016/j.vetmic.2009.09.020. 